University of Nebraska - Lincoln

DigitalCommons@University of Nebraska - Lincoln

Drought Mitigation Center Faculty Publications Drought - National Drought Mitigation Center

2005

\title{
The Effect of the Length of Record on the Standardized Precipitation Index Calculation
}

\author{
Hong Wu \\ University of Nebraska-Lincoln \\ Michael J. Hayes \\ University of Nebraska-Lincoln, mhayes2@unl.edu \\ Donald A. Wilhite \\ University of Nebraska - Lincoln, dwilhite2@unl.edu \\ Mark D. Svoboda \\ University of Nebraska-Lincoln, msvoboda2@unl.edu
}

Follow this and additional works at: https://digitalcommons.unl.edu/droughtfacpub

Wu, Hong; Hayes, Michael J.; Wilhite, Donald A.; and Svoboda, Mark D., "The Effect of the Length of Record on the Standardized Precipitation Index Calculation" (2005). Drought Mitigation Center Faculty Publications. 39.

https://digitalcommons.unl.edu/droughtfacpub/39

This Article is brought to you for free and open access by the Drought -- National Drought Mitigation Center at DigitalCommons@University of Nebraska - Lincoln. It has been accepted for inclusion in Drought Mitigation Center Faculty Publications by an authorized administrator of DigitalCommons@University of Nebraska - Lincoln. 
Published in International Journal of Climatology 25 (2005), pp. 505-520; doi: 10.1002/joc.1142. Copyright (C) 2005 Royal Meteorological Society. Published online in Wiley InterScience. Used by permission.

Submitted June 17, 2004; revised September 20, 2004; accepted November 15, 2004.

\title{
The Effect of the Length of Record on the Standardized Precipitation Index Calculation
}

\author{
Hong Wu, Michael J. Hayes, Donald A. Wilhite, and Mark D. Svoboda
}

National Drought Mitigation Center, University of Nebraska, Lincoln, NE 68583-0728, USA

Corresponding author - Hong Wu, National Drought Migration Center University of Nebraska, Lincoln, NE 685830728, USA; email hwu2@unl.edu

\begin{abstract}
The effect of the length of record on the standardized precipitation index (SPI) calculation was investigated by examining correlation coefficients, the index of agreement, and the consistency of dry/wet event categories between SPI values derived from different precipitation record lengths. The effect was also illustrated by comparing SPI values derived from different lengths of record in some severe drought and flood years, and by comparing drought intensities based on SPI values temporally and spatially. Furthermore, the reason for the SPI value discrepancy was explored by investigating the changes of the shape and scale parameters of the gamma distribution when different lengths of record were involved. The gamma distribution is a frequency distribution of climatological precipitation time series and is the basis of the SPI calculation used in this analysis. The results show that SPI values computed from different lengths of record are highly correlated and consistent when the gamma distributions of precipitation over the different time periods are similar. However, the SPI values are significantly discrepant when the distributions are different. It is recommended that the SPI user should be aware of the numerical difference of the SPI values if different lengths of record are used in interpreting and making decisions based on SPI values.
\end{abstract}

Keywords: Nebraska, standardized precipitation index (SPI), length of precipitation record, time scale, gamma distribution 


\section{Introduction}

In order to give a better representation of abnormal wetness and dryness than the Palmer indices, McKee et al. (1993) developed the standardized precipitation index (SPI), which only requires data for precipitation, based on the premise that precipitation deficits over varying periods or time scales influence groundwater, reservoir storage, soil moisture, snowpack, and streamflow. Comparing historical time series of the Palmer drought index (PDI; Palmer, 1965) with time series of the corresponding SPI through spectral analysis, Guttman (1998) concluded that the spectral characteristics of the PDI change from place to place across the USA and the PDI has a complex structure with an exceptionally long memory, whereas the SPI is spatially consistent and has a simple structure. An important characteristic of the SPI is that it can monitor dry and wet periods over a wide spectrum of time scales (Edwards and McKee, 1997), allowing users to choose the time scale most appropriate for their particular application to compute the SPI. Guttman (1999) strongly suggested that users interested in the Palmer indices consider using the SPI as either a main drought index or as an equal partner to the Palmer indices.

This study investigates the effect of a station's length of record for precipitation on the SPI calculation. Several techniques were investigated, including the examination of correlation coefficients, the index of agreement, and the consistency of dry/wet event categories between SPI values derived from different precipitation record lengths at the same station.

SPI values derived from different lengths of record were also compared for particular severe drought and flood years. This study will hopefully provide some guidelines to researchers trying to use the SPI for drought analyses when they have data from stations with a variety of lengths of record.

\section{SPI Background}

Hayes et al. (1999) demonstrated how the SPI at varying time scales could have been used operationally to monitor the 1996 drought from its development to its conclusion in the southern Great Plains and the southwestern USA. They concluded that "using the SPI as a drought monitoring tool will improve the timely identification of emerging drought conditions that can trigger appropriate state and federal actions." Researchers also compared the monitoring capabilities between the Palmer drought severity index (PDSI) and 3 and 12 month SPIs for the drought of 1983 that occurred in southeastern Hungary. It was demonstrated that the SPI, with multiple time scales, is a better tool for detecting the start and end of a drought event (Szalai and Szinell, 2000). Lloyd-Hughes and Saunders (2002) compared the SPI calculated at a $0.5^{\circ}$ grid across the whole of Europe over time scales of 3 to 24 months with the PDSI. They concluded that the SPI provides better spatial standardization than the PDSI with respect to extreme drought events, and the SPI is a simple and effective tool for drought climatology analysis. In another study, the SPI was successfully used as a tool to detect rainfall patterns in northeast Spain (Lana et al., 2001). The SPI, in addition, was used for real-time monitoring or retrospective analysis of drought/flood in Argentina (Seiler et al., 2002), Canada (Anctil et al., 2002), Korea (Min et al. 2003) and South Africa (Rouault and Richard, 2003). After evaluating 14 well-known drought indices by 
using a weighted set of six evaluation criteria, Keyantash and Dracup (2002) found that the SPI is a valuable estimator of drought severity.

In the USA, the SPI is employed to monitor the current status of drought on regional scales ranging from specific states, such as Colorado (CCC, 2004), to the whole country by the Western Regional Climate Center (WRCC, 2004), the National Drought Mitigation Center (NDMC, 2004) and the National Climatic Data Center (NCDC, 2004). On a global scale, the NDMC is aware of about 60 countries using the SPI for drought monitoring and drought research.

Determination of a probability density function is an essential step in the SPI calculation. Guttman (1999) compared SPI values computed from six different probability functions, including: the two-parameter gamma (GAM); the two-parameter gamma (CSU), for which the parameters are estimated by the maximum likelihood method; the three-parameter Pearson type III (PE3); the three-parameter generalized extreme value (GEV); the fourparameter kappa (KAP); and the five-parameter Wakeby (WAK). He concluded that the PE3 distribution is the best universal model for the SPI calculation. This study chose the two-parameter gamma distribution (CSU) for the further analyses because the CSU model is currently used by the NDMC, WRCC, and the National Agricultural Decision Support System (NADSS, 2004) and because the SPI computing software package based on the CSU model has been distributed to about 60 countries. We recognize that the PE3 model has also been widely distributed and used, but standardizing the calculation algorithms is an issue that is beyond the scope of this article.

According to Edwards and McKee (1997), a gamma probability density function to a given frequency distribution of precipitation totals for the station of interest is fitted as

$$
g(x)=\frac{1}{\beta^{\alpha} \Gamma(\alpha)} x^{\alpha-1} \mathrm{e}^{-x / \beta} \quad \text { for } x>0
$$

where $\alpha$ is a shape parameter $(\alpha>0), \beta$ is a scale parameter $(\beta>0), x$ is the precipitation amount $(x>0)$, and

$$
\Gamma(\alpha)=\int_{0}^{\infty} y^{\alpha-1} \mathrm{e}^{-y} \mathrm{~d} y
$$

where $\Gamma(\alpha)$ is the gamma function.

Then the shape parameter $\alpha$ and the scale parameter $\beta$ are estimated for each time scale of interest (either weeks or months) and for each week or month of the year, depending on whether the weekly or monthly SPI is calculated:

$$
\begin{aligned}
& \hat{\alpha}=\frac{1}{4 A}\left(1+\sqrt{1+\frac{4 A}{3}}\right) \\
& \hat{\beta}=\frac{\bar{x}}{\hat{\alpha}}
\end{aligned}
$$


where $\mathrm{A}=\ln (\bar{x})-[\Sigma \ln (x)] / n, n$ is number of precipitation observations, and $\bar{x}$ is mean precipitation over the time scale of interest.

The cumulative probability of each observed precipitation event for the given time scale for the station of interest is then computed using the estimated shape and scale parameters. An equiprobability transformation is made from the cumulative probability to the standard normal random variable $Z$ with mean zero and variance of one, where the SPI takes on the value of $Z$.

The length of record for precipitation used in the SPI calculation is "ideally a continuous period of at least 30 years" (McKee et al., 1993). However, Guttman (1994) investigated the effect of sample size on precipitation distribution fitted by L-moments and found that about 40-60 years of record is needed for parameter estimation stability in the central part of the distribution, and about 70-80 years of record for stability in the tails, which are important in the use of the SPI. For a stable estimation of the gamma distribution parameters, the required length of record is even longer.

Unfortunately, the 30-year record requirement cannot be met in some developing countries. Even in the USA, the precipitation record length varies from one station to another across the region of interest. In Nebraska, for instance, among the 201 Cooperative Observer Program (COOP) stations with precipitation records that span at least 30 years, the beginning years of precipitation record vary from 1880 to 1971 . Because the SPI is a probability-related index, the longer the length of record the more confidence there is in the stability of the underlying statistics. Therefore, it is to be expected that researchers would choose to keep the length of precipitation data used in the SPI calculation as long as possible for the station of interest.

Because the climate is constantly changing and fluctuating (Landsberg, 1975; Burroughs, 2001), different time periods have different climate conditions. Skaggs (1978) found that the climate of western Kansas remained unchanged, but the variance and degree of persistence of climatic states fluctuated substantially. Some other regions have also experienced significant changes in precipitation (Houghton et al., 1992). Precipitation fluctuations of $25 \%$ or more, for 10-20 years' duration, were detected in the US climate records between 1931 and 1982 (Karl and Riebsame, 1984). The World Meteorological Organization (WMO) recommended the 30-year normals in order to reduce the influence of varying observation practices and natural climatic fluctuations (Lamb and Changnon, 1988). A recent study has noted significant departures from long-term stationarity in the US precipitation record at the end of the 20th century (Mauget, 2003).

These climate characteristics raise questions about the sensitivity of SPI values to different record lengths and different time periods of record. Are SPI values related to the length of record for precipitation involved in the SPI calculation or to the distribution of precipitation over the time period of the record? The objective of this study is to investigate the effect of precipitation record length on SPI values calculated from the CSU model. 


\section{Methods}

The Nebraska, USA, region is examined in this study. Variability of year-to-year precipitation amount is a major characteristic of Nebraska's precipitation (Wilhite, 1981). Eight climate divisions within the state represent climatically homogeneous regions (Karl and Riebsame, 1984), as illustrated in figure 1. Two weather stations in each climate division were selected, giving 16 in total. Table I lists the names and record periods of the stations selected. As seen in table I, the record length varies from station to station, with beginning dates ranging from 1887 to 1948.

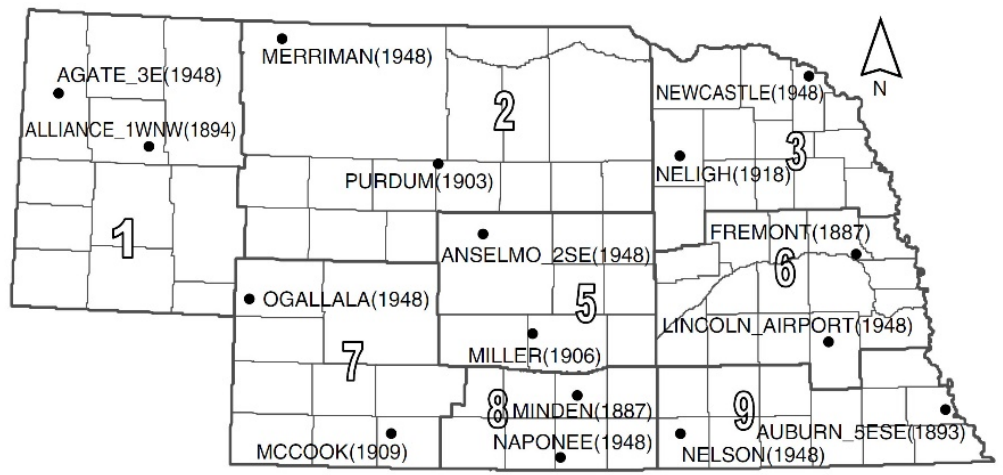

Figure 1. Distribution of 16 COOP stations and climatic divisions in Nebraska. Station names are followed by the beginning years of precipitation records. Numbers on the map denote climatic divisions.

Table I. Long and short lengths of record used in SPI calculation for the 16 stations

\begin{tabular}{lccc}
\hline & & \multicolumn{2}{c}{ Length of record used in SPI calculation } \\
\cline { 3 - 4 } Station (record period) & Time period of SPI values & Long length & Short length \\
\hline Minden (1884-2003) & $1931-2000$ & $1884-2000$ & $1931-1960$ \\
Fremont (1887-2003) & $1971-2000$ & $1884-2000$ & $1971-2000$ \\
Auburn_5ESE (1893-2003) & $1931-2000$ & $1887-2000$ & $1931-1960$ \\
Alliance_1WNW (1894-2003) & $1971-2000$ & $1887-2000$ & $1971-2000$ \\
Purdum (1903-2003) & $1931-2000$ & $1893-2000$ & $1931-1960$ \\
Miller (1906-2003) & $1971-2000$ & $1893-2000$ & $1971-2000$ \\
& $1931-2000$ & $1894-2000$ & $1931-1960$ \\
McCook (1909-2003) & $1971-2000$ & $1894-2000$ & $1971-2000$ \\
& $1931-2000$ & $1903-2000$ & $1931-1960$ \\
& $1971-2000$ & $1903-2000$ & $1971-2000$ \\
& $1931-2000$ & $1906-2000$ & $1931-1960$ \\
& $1971-2000$ & $1906-2000$ & $1971-2000$
\end{tabular}




\begin{tabular}{lccc} 
Neligh (1918-2003) & $1931-2000$ & $1918-2000$ & $1931-1960$ \\
Agate_3E (1948-2003) & $1971-2000$ & $1918-2000$ & $1971-2000$ \\
Anselmo_2SE (1948-2003) & $1931-2000$ & N/A & N/A \\
& $1971-2000$ & $1948-2000$ & $1971-2000$ \\
Lincoln_Airport (1948-2003) & $1931-2000$ & N/A & N/A \\
& $1971-2000$ & $1948-2000$ & $1971-2000$ \\
Merriman (1948-2003) & $1931-2000$ & N/A & N/A \\
& $1971-2000$ & $1948-2000$ & $1971-2000$ \\
Naponee (1948-2003) & $1931-2000$ & N/A & N/A \\
Nelson (1948-2003) & $1971-2000$ & $1948-2000$ & $1971-2000$ \\
Newcastle (1948-2003) & $1931-2000$ & N/A & N/A \\
& $1971-2000$ & $1948-2000$ & $1971-2000$ \\
Ogallala (1948-2003) & $1931-2000$ & N/A & N/A \\
& $1971-2000$ & $1948-2000$ & $1971-2000$ \\
& $1931-2000$ & N/A & N/A \\
\hline
\end{tabular}

N/A denotes the data in this period are not available.

The period in parentheses beside each station's name is the record period for that station.

The daily precipitation data used in this study were obtained from the High Plains Regional Climate Center (HPRCC, 2004). The C++ code, developed by the Department of Computer Science and Engineering at the University of Nebraska-Lincoln, was used to calculate SPI values for this study (NADSS, 2004). The six time scales of SPI values studied were $12,24,36,52,104$, and 156 weeks. When computing SPI values at long time scales, like 104 and 156 weeks, one needs to be aware that the effective sample sizes of 104 and 156 weeks are respectively one-half and one-third that of 52-week samples (Guttman, 1999). As a result, the confidence in the SPI values for the longer time scales decreases. This study included such long time scales because calculating 2- or 3-year SPI values is a common practice (e.g., NCDC provides 1- to 24-month SPI maps, CCC provides 1- to 48-month SPI maps, and WRCC provides 1- to 72-month SPI maps). Differences between the SPI values computed from different lengths of record were examined in four ways.

First, SPI values for the six time scales were calculated for two 30-year time periods (1931-60 and 1971-2000) using the stations' lengths of record indicated in table I. Eight stations began recording precipitation data before 1931, with the remainder beginning data collection in 1948. Thus, the SPI values based on the long length of record for the period 1931-60 could only be calculated for these eight stations, whereas the SPI values for the period 1971-2000 were calculated for all 16 stations. Furthermore, the SPI values based on the short length of record for the same two periods were calculated using the precipitation records of the 30-year period 1931-60 for the same eight stations and for 1971-2000 for all 16 stations. The SPI values derived using the long length of record were paired with the values derived using the short length of record to conduct comparisons. 
Table I also summarizes the different lengths of record used to calculate SPI values for each station. For example, the SPI values for the periods 1931-60 and 1971-2000 for the Alliance 1WNW station were calculated using the records for 1894-2000, 1931-60, and 1971-2000. Then the SPI values computed from the two shorter lengths of record were correspondingly pairwise compared with those computed based on the 1894-2000 data for each of the six time scales mentioned above.

The linear correlation coefficient $r$, which measures the strength of the linear relationship between the paired SPI values derived from different lengths of record, was computed for the six time scales for each station. Ranks of SPI values during a certain time period are an important indicator of the intensity of drought/wet events. A rank was assigned to each individual SPI value according to its order in the ranked list. Then Spearman's rank correlation coefficients $r_{s}$ (Triola, 1998) between the paired SPI values were computed, which uses ranks as the basis for measuring the strength of the association between two SPI values.

The linear correlation coefficient has been widely used to describe a consistent proportional increase or decrease between two variables. However, it is unable to distinguish the type or magnitudes of possible covariations. The index of agreement ( $D$ index) is sensitive to differences between two variables and reflects the degree to which one variables is accurately estimated by another (Willmott, 1981). Thus, the $D$ index between the paired SPI values was also computed.

Second, event intensities were categorized. Drought/wet intensity can be defined as "extremely dry, severely dry, . . ., very wet or extremely wet" to indicate the severity of a drought/wet event clearly. Drought/wet event intensities resulting from the SPI values during 1931-60 and 1971-2000 were categorized according to this classification system (table II); then the consistency between the event intensities derived from the long and short lengths of record were checked for each station for the six time scales.

\begin{tabular}{ll}
\hline $\begin{array}{r}\text { Table II. The SPI classification system } \\
\text { (McKee et al., 1993) }\end{array}$ \\
\hline SPI values & Category \\
\hline 2.0 and above & Extremely wet \\
1.5 to 1.99 & Very wet \\
1.0 to 1.49 & Moderately wet \\
-0.99 to 0.99 & Near normal \\
-1.0 to -1.49 & Moderately dry \\
-1.5 to -1.99 & Severely dry \\
-2.0 and less & Extremely dry \\
\hline
\end{tabular}

Third, the SPI values derived from different lengths of record were also compared in individual severe drought and flood years for the recorded history of Nebraska. The drought of the 1930s was the longest dry period for Nebraska in recent history (Lawson et al., 1971), often referred to as the Dust Bowl. The drought year of 1974 was the most severe of the mid-1970s for Nebraska, resulting in more than US\$10 million in losses in eight counties (Wilhite, 1983). From May to September of 1993, record flooding occurred across 
the Midwest region of the USA, including Nebraska. Fifty people died due to the flooding, and damages approached US\$15 billion (Larson, 1996). The 2002 drought caused a loss of US $\$ 1.2$ billion in agriculture in Nebraska (IANR, 2003). In this case, the individual years in which SPI values derived from different lengths of record were compared were 1936-39, 1974-77, 1992-94, and 2001-03. Since 2001-03 was involved in the study, the previous period 1971-2000 was extended to 1971-2003 to conduct the analyses by recalculating the shape and scale parameters using the three additional years of data.

Last, the SPI values derived from the different lengths of record were compared temporally and spatially. Comparing drought intensity temporally is often conducted in order to put the current status of drought into a historical perspective for practical reasons. For instance, policy makers or farmers are interested in the development of a drought's intensity over a certain period of time. The development and intensity of the 2002 drought was examined using the SPI values derived from different lengths of record. In addition, it is also a common practice to compare SPI values from different locations in a region to understand dry/wet intensity distributions. This study compared two stations' SPI values derived from different record lengths to illustrate that the length of record used to calculate the SPI values would alter the conclusion.

\section{Results and Discussion}

\subsection{Comparisons of correlation coefficients and $D$ index}

Overall, the values of the linear correlation coefficients $r$, rank correlation coefficient $r_{\mathrm{s}}$ and index of agreement $D$ between the paired SPI values for all stations indicated that the SPI values derived from the long lengths of record are highly correlated with those from the short lengths for all six time scales within the two periods 1931-60 and 1971-2000 because the values were greater than or close to 0.9 in the majority of the cases. In most cases, the values of correlation coefficients $r$ and rank correlation coefficients $r_{\mathrm{s}}$ at longer time scales are higher than those at shorter time scales.

Unlike $r$ and $r_{\mathrm{s}}$, the $D$ index did not increase with the time scales of SPI values. In some cases, the $D$ index even decreased with longer time scales. Generally, the $D$ index was greater than $r$ at the shorter time scales and smaller than $r$ at the longer time scales. It was found that the $D$ index indicates the consistency between the paired SPI values better because the numerical difference among the SPI values increases for longer time scales. This will be discussed later. Table III lists the values of the $r, r_{\mathrm{s}}$, and $D$ index between the SPI values derived from the periods 1887-2000, 1931-60, and 1971-2000 for the Minden station. 
Table III. Summary of linear correlation coefficients $r$, rank correlation coefficients $r_{\mathrm{s}}$ and index of agreement $D$ between the SPI derived for 1887-2000, and those for 1931-60 and 1971-2000 for Minden, Nebraska

\begin{tabular}{llcccccc}
\hline & & $\begin{array}{c}\text { 12-week } \\
\text { SPI }\end{array}$ & $\begin{array}{c}\text { 24-week } \\
\text { SPI }\end{array}$ & $\begin{array}{c}\text { 36-week } \\
\text { SPI }\end{array}$ & $\begin{array}{c}\text { 52-week } \\
\text { SPI }\end{array}$ & $\begin{array}{c}\text { 104-week } \\
\text { SPI }\end{array}$ & $\begin{array}{c}\text { 156-week } \\
\text { SPI }\end{array}$ \\
\hline SPI for period 1931-60 & $r$ & 0.985 & 0.990 & 0.996 & 0.999 & 1.000 & 1.000 \\
& $r_{\mathrm{s}}$ & 0.989 & 0.991 & 0.996 & 1.000 & 1.000 & 0.999 \\
& $D$ & 0.986 & 0.984 & 0.984 & 0.978 & 0.958 & 0.942 \\
SPI for period 1971-2000 & $r$ & 0.988 & 0.992 & 0.993 & 0.999 & 0.998 & 0.999 \\
& $r_{\mathrm{s}}$ & 0.990 & 0.993 & 0.996 & 0.999 & 0.999 & 0.999 \\
& $D$ & 0.993 & 0.993 & 0.992 & 0.991 & 0.982 & 0.972 \\
\hline
\end{tabular}

\subsection{Comparisons of consistency of event category}

Although $r, r_{\mathrm{s}}$, and the $D$ index all indicate that the SPI values derived from different lengths are highly correlated, it was felt that it would be interesting to check the consistency of the drought/wet event category resulting from different data-length-derived SPI values. The consistency was determined as follows. If an event category derived from the long lengths of record was consistent with that from the short lengths, it was called a "match." Otherwise, it was called a "no-match." Then a no-match percentage was obtained by dividing the numbers of no-match by the total numbers of match and no-match. Furthermore, in order to show the degree of the "no-match," the number of times the match is off by more than one category was counted. This occurs, for example, when an SPI value derived from the long length of record is classified into the near-normal category and the corresponding SPI value derived from the short length is classified into a severely dry or extremely dry category.

Generally, the no-match percentages for 12- and 24-week SPIs were close among all stations, ranging from 10 to $20 \%$. As the time scales get longer, the discrepancies for some stations become significant. For the 156-week SPI, the no-match percentages ranged from 10 to $60 \%$. It was also noted that $97.7 \%$ of the no-match cases are off by only one category. In addition, it was found that the degree of the no-match percentage is not related to the difference of the record lengths used to derive the SPI values. For instance, the no-match percentages for the Alliance station are lower than those for the Anselmo station, even though the length of record for Alliance is longer (table IV). The number of times the match is off by more than one category for Anselmo is much higher than the number for Alliance, especially at the longer time scales. It was also noticed that the no-match percentages for Alliance 1931-60 are higher than for 1971-2000 according to table IV. Figure 2 shows two clustered bar graphs comparing the consistency of the dry/wet category resulting from SPI values computed using different lengths of record for Neligh and Auburn, Nebraska. The SPI values for Neligh were derived for 1918-2000 and 1971-2000. The SPI values for Auburn were derived for 1893-2000 and 1971-2000. As shown, although the percentages for no-match are the same for the 12-week SPI for the two stations, the percentages for Neligh increase dramatically from 16 to $62 \%$ as the SPI time scales become longer, and so does the number of times the match is off by more than one category. On the other hand, the percentages for Auburn decrease from $16 \%$ to $10 \%$ as the time scales become longer. 
Table IV. No-match percentages of drought/wet event category for Alliance (derived 1894-2000 and 1931-60, 1971-2000), and for Anselmo (derived for 1948-2000 and 1971-2000)

\begin{tabular}{lllllll}
\hline Station & $\begin{array}{c}\text { 12-week } \\
\text { SPI (\%) }\end{array}$ & $\begin{array}{c}\text { 24-week } \\
\text { SPI (\%) }\end{array}$ & $\begin{array}{c}\text { 36-week } \\
\text { SPI (\%) }\end{array}$ & $\begin{array}{c}\text { 52-week } \\
\text { SPI (\%) }\end{array}$ & $\begin{array}{c}\text { 104-week } \\
\text { SPI (\%) }\end{array}$ & $\begin{array}{c}\text { 156-week } \\
\text { SPI (\%) }\end{array}$ \\
\hline Alliance (1931-60) & $16.8(2)$ & $17.9(0)$ & $20.1(0)$ & $12.6(0)$ & $17.0(0)$ & $23.5(0)$ \\
Alliance (1971-2000) & $15.2(1)$ & $10.8(1)$ & $13.9(0)$ & $12.1(0)$ & $6.6(0)$ & $14.9(0)$ \\
Anselmo (1971-2000) & $19.2(7)$ & $22.0(6)$ & $21.1(22)$ & $24.6(26)$ & $26.3(55)$ & $24.5(54)$ \\
\hline
\end{tabular}

The period in the parentheses beside each station's name is the period of SPI values compared.

The numbers in parentheses next to the no-match percentages are the numbers of times the match is off by more than one category.
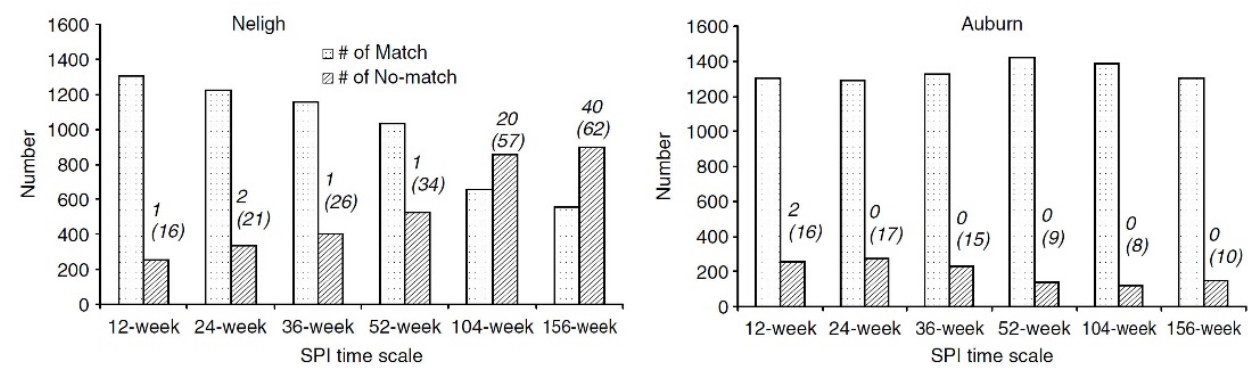

Figure 2. Clustered bar chart showing the consistency of drought category resulting from the SPI values derived for 1918-2000 and 1971-2000 for Neligh (left) and for 1893-2000 and 1971-2000 for Auburn (right). Light gray bars denote the number of matches. Dark gray bars denote the number of no-matches. The numbers appearing above the "nomatch" bars denote the numbers of times the match is off by more than one category. The percentages of the "no-match" are shown in parentheses.

\subsection{Comparisons of SPI values in individual years}

In individual severe drought/flood years, the SPI values derived from different lengths of record match well for some stations, whereas the SPI values at long time scales differ considerably for other stations, especially in intense drought years. Figure 3 shows the comparisons of SPI values computed with data for 1936-38, 1992-94 and 2001-03 for Miller using different lengths of record. SPI values derived from different lengths of record are compared at short (24 weeks) and long (52 weeks) time scales. As shown, the SPI values match up very well with each other for these individual years going from shorter to longer time scales in both dry and wet years. In addition, figure 4 shows the comparisons of SPI values for McCook for the same years at the same two time scales. As can be seen, the 52week SPI values for 1936-38 and 1992-94 are different, but the differences are not considerable (the differences range from 0.7 to 0 ). However, the 52-week SPI value discrepancies become significant when drought intensifies during 2001-03. The SPI values derived for 1971-2003 reach to about -2.7 , whereas the corresponding SPI values derived for 19092003 are only about -1.5 . In this case, different lengths of record used to compute SPI could result in different evaluations of the severity of severe droughts. 

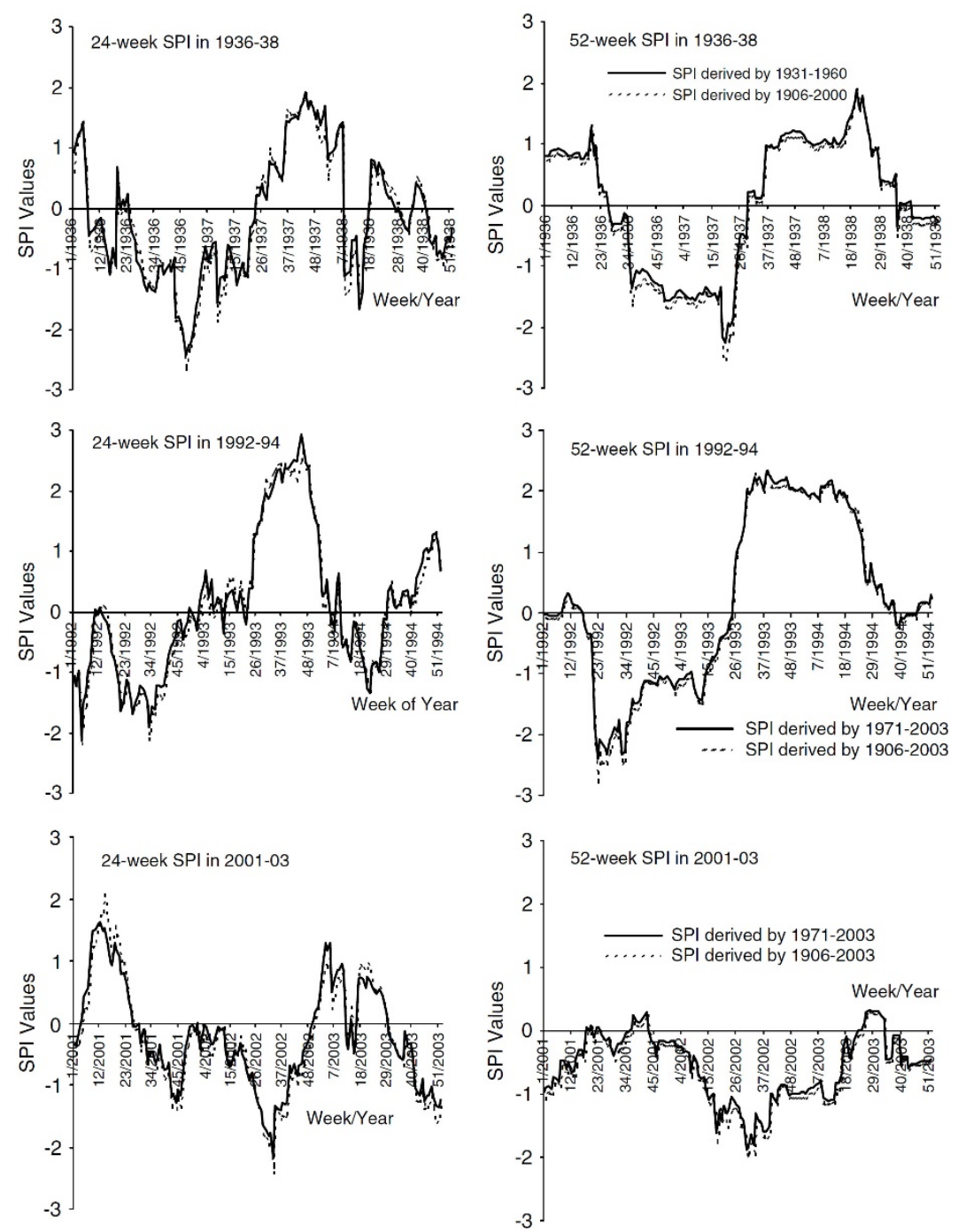

Figure 3. The SPI values in 1936-38, 1992-94, and 2001-03 derived for the 1906-2000 (or 2003), 1931-60, and 1971-2003 records for Miller, Nebraska. The solid line denotes SPI values derived from the short length of record. The dotted line denotes SPI values derived from the long length of record. 

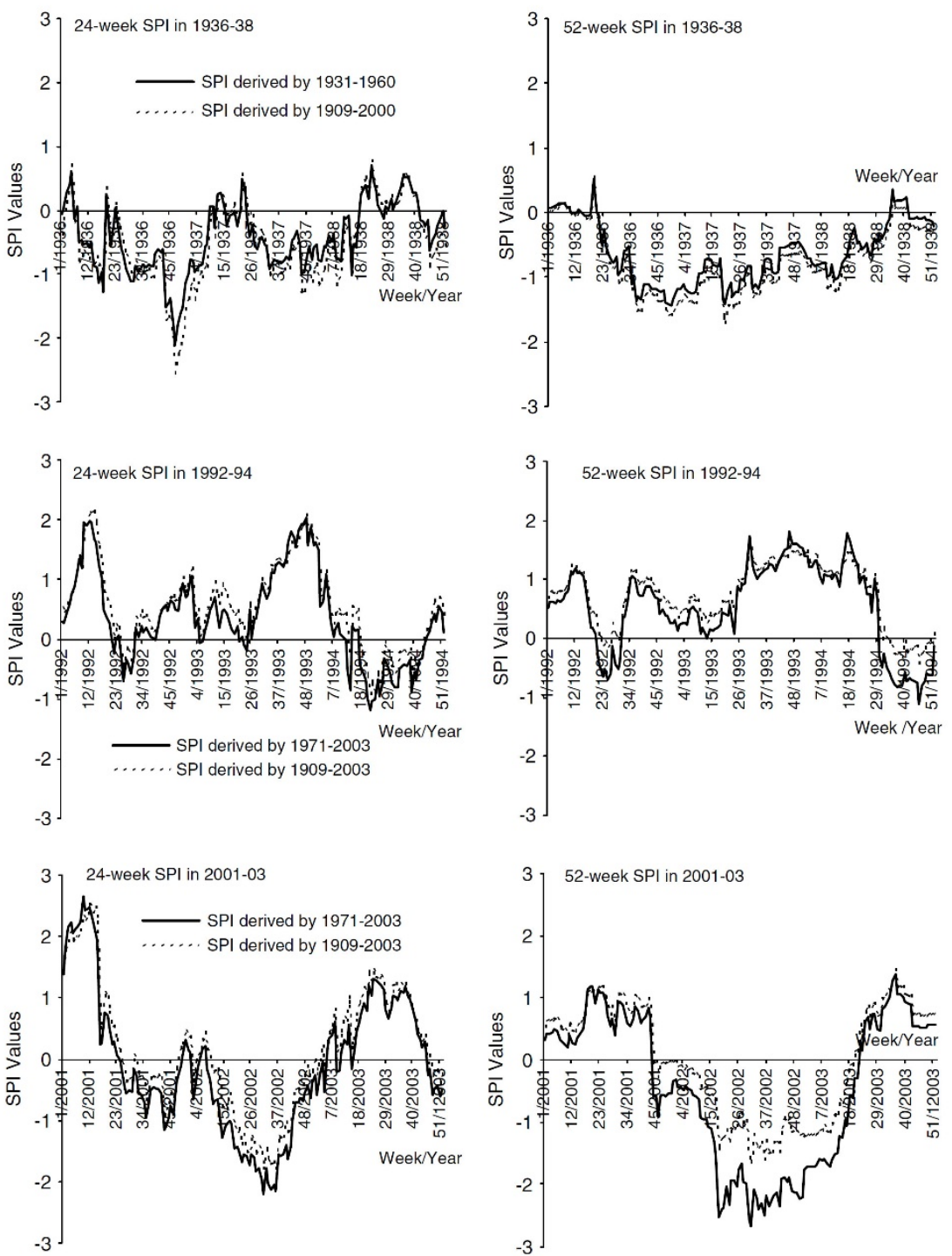

Figure 4. The SPI values in 1936-38, 1992-94, and 2001-03 derived for the 1909-2000 (or 2003), 1931-60, and 1971-2003 records for McCook, Nebraska. The solid line denotes SPI values derived from the short length of record. The dotted line denotes SPI values derived from the long length of record.

\subsection{Spatial and temporal comparisons of SPI values}

Figure 5(a) shows the 24-week SPI development during 2002 derived using data for 19712003 and for 1894-2003 for Alliance, Nebraska. As seen, the spikes of the SPI values for 1971-2003 indicate that the intensities during 17th, 26th, 33rd, and 42nd weeks of 2002 were about the same (between -3 and -3.5), meaning that the intensity of the 2002 drought was steady. However, the SPI values derived for 1894-2003 show that the intensity of drought decreases from -4 to -2.5 over the same period. 
Figure 5(b) compares the 52-week SPI values between McCook and Ogallala, Nebraska, during the 7th to 20th weeks of 2002. Water availability during this period is critical for crop planting and growing. If the SPI values derived for 1971-2003 are used, then the 2002 drought intensity for McCook was stronger than that of Ogallala after the 12th week of the year. If the available precipitation records of these two stations are used, however, then the comparison of the SPI values derived for 1948-2003 (for Ogallala) and 1909-2003 (for McCook) show that the drought intensities of the two stations were about the same after the 12 th week.
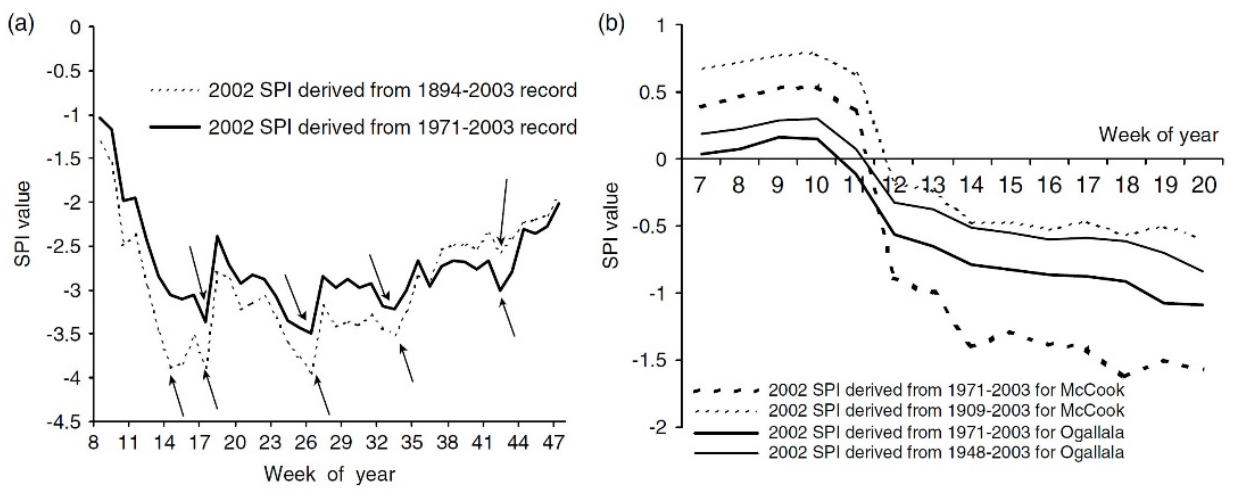

Figure 5. (a) Illustration of development of the 2002 drought in 2002 for Alliance, Nebraska. The solid line denotes 24-week SPI values derived for 1971-2003. The dotted line denotes 24-week SPI values derived for 1894-2003. (b) Comparison of 52-week SPI values for McCook and Ogallala, Nebraska. The thin dotted line denotes SPI values derived for 1909-2003 for McCook. The heavy dotted line denotes SPI values for 1971-2003 for McCook. The thin solid line denotes SPI values for 1948-2003 for Ogallala. The heavy solid line denotes SPI values for 1971-2003 for Ogallala.

These two examples show how different conclusions can be obtained if the lengths of record used in the SPI calculation are different. The SPI user should be aware of this fact when doing research or making decisions.

\subsection{Reasons for the SPI value discrepancy}

The results illustrated above show that SPI values calculated using different lengths of record are similar for some stations but are significantly different at other stations, especially for long-time-scale SPI values in severe drought years. To find the reasons the SPI values were discrepant at some of the stations, the following efforts were made.

First, the precipitation record was graphed against time to reveal any variability existing in the record. Figure 6 illustrates the 1-, 2-, and 3-year precipitation totals for Miller and McCook. This figure indicates that both stations' time series show considerable interannual variability, as expected. The major difference between the two stations is that McCook has an increasing trend in precipitation amount whereas the Miller series does not suggest any change in central tendency over time. 

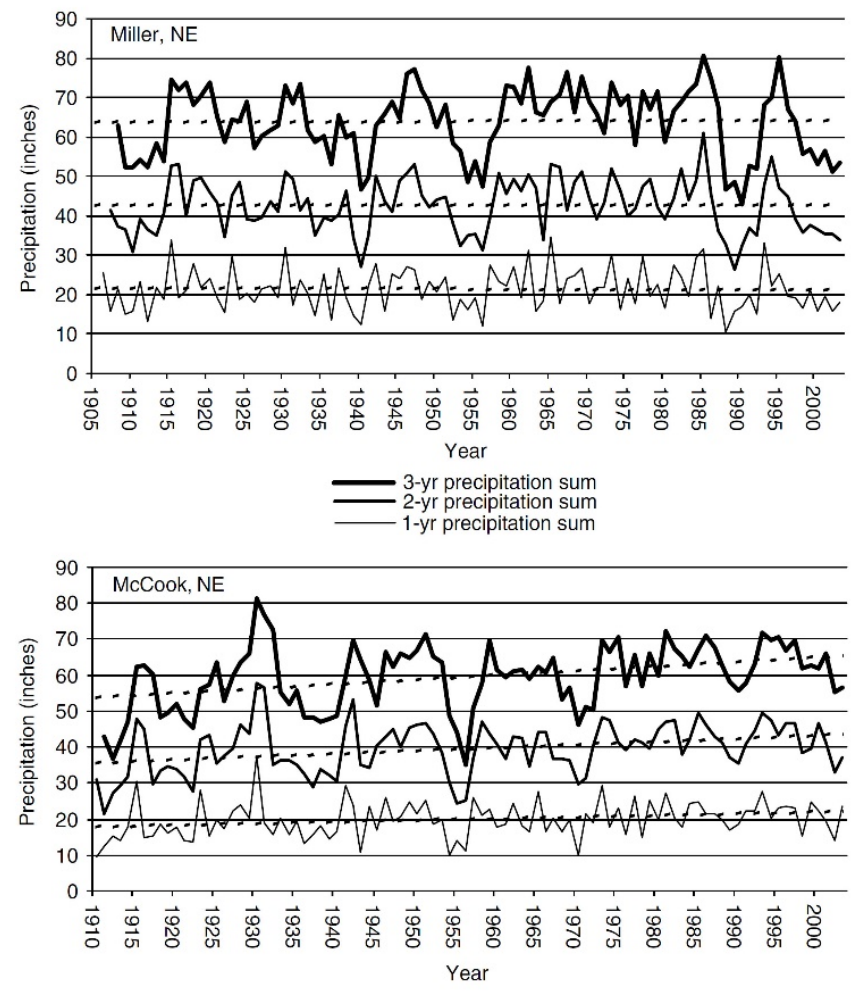

Figure 6. Miller and McCook, Nebraska, precipitation record based on 1-, 2-, and 3-year totals. The dashed lines are the long-term trend lines.

Next, the SPI calculation equations were investigated. The $\alpha$ and $\beta$ were computed using the long and short lengths of record for the 16 stations, for the six time scales, and for each week of the year. After inspecting the parameters for multiple time scales over the long and short lengths of record, it is found that if the $\alpha$ and $\beta$ derived from the long and short lengths of record are similar, that is the distributions of precipitation over the different periods are similar, then the SPI values will be consistent. On the other hand, if the differences in the parameters are significant, then the SPI values will be considerably different. Figure 7 suggests that the $\alpha$ and $\beta$ values derived from three different lengths of record of the 52-week SPI for each week of a year for McCook are considerably different, yet they are nearly the same for Miller. To illustrate the effects of the $\alpha$ and $\beta$ values on the SPI values schematically, figure 8 shows the gamma probability density functions (PDFs) at the time scale of 52 weeks derived from three lengths of record (1906-2000, 1971-2000, and 1931-60) on the 12th week of a year for Miller, in which the SPI values derived from different lengths of record matched very well (fig. 3). As can be seen, the PDF curves derived from the different lengths of record are close to each other because the parameters $\alpha$ and $\beta$ are similar. In contrast, figure 9 shows the PDF at the 52-week time scale derived for 19092000, 1971-2000, and 1931-60 for McCook, in which the SPI values differed considerably at long time scales during severe drought years from 2001 to 2003 (fig. 4). The parameters 
derived for 1909-2000 and 1931-60 are similar, whereas the parameters are significantly different between 1909-2000 and 1971-2000. Furthermore, the gamma cumulative probability distribution functions (CDFs) were obtained based on the PDFs shown in figure 10 for McCook. Obviously, the CDFs illustrated in figure 10 indicate that the CDF derived for 1971-2000 is different from the other two CDFs derived for 1909-2000 and 1931-60, especially on the left-hand side (or when precipitation is less than a certain amount). Consequently, the SPI values will be different when the equiprobability transformation is made from CDFs to the standard normal distribution when precipitation is less than a certain amount.
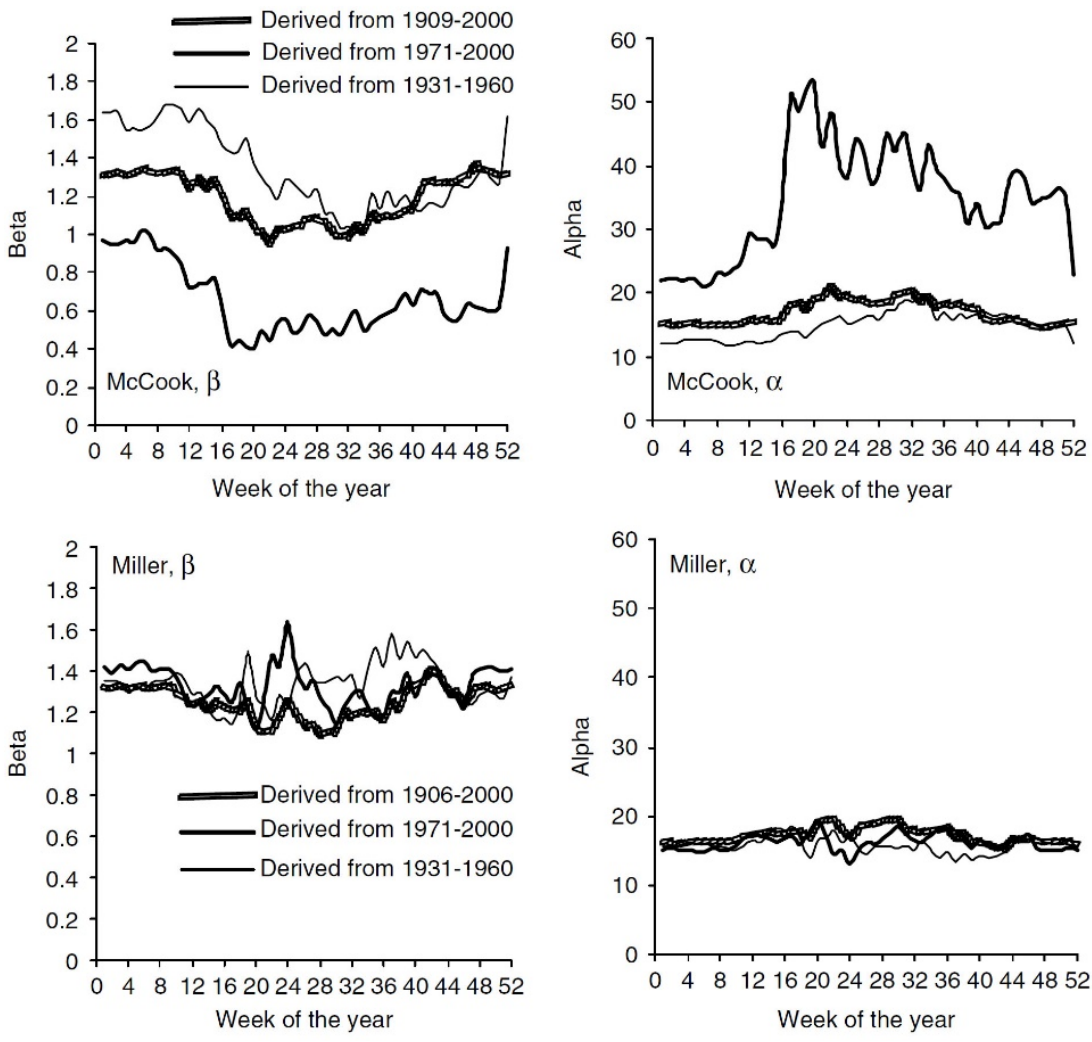

Figure 7. The values of $\alpha$ and $\beta$ derived for 1906-2000, 1931-60, and 1971-2000 for each week of a year for McCook and Miller, Nebraska. 


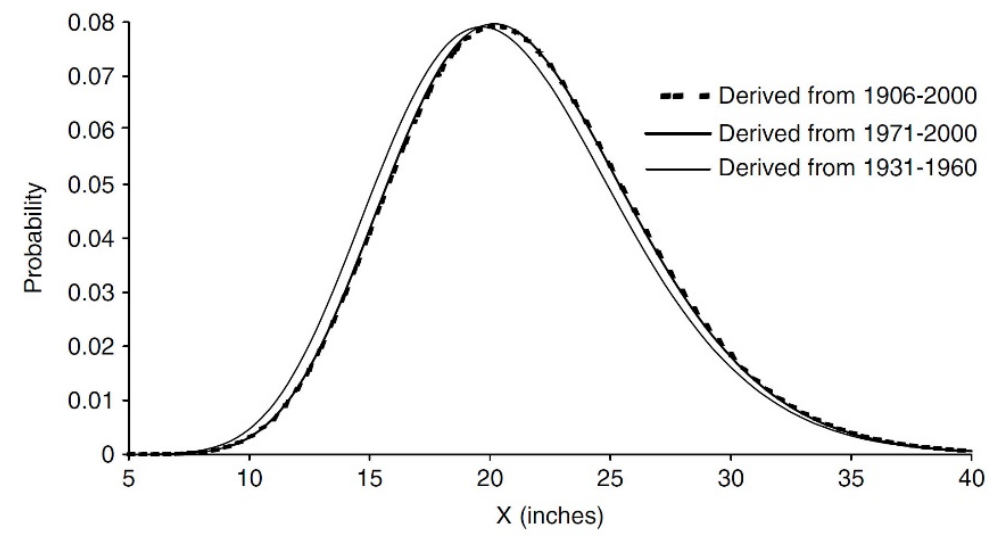

Figure 8. Two-parameter gamma PDF curves for 52-week SPI for Miller, Nebraska. The heavy solid line denotes the PDF derived from the 1971-2000 records with $\alpha=17.39, \beta=$ 1.23. The dotted line denotes the PDF derived from the 1906-2000 records with $\alpha=17.31$, $\beta=1.24$. The thin solid line denotes the PDF derived from the 1931-60 records with $\alpha=$ $16.35, \beta=1.28$.

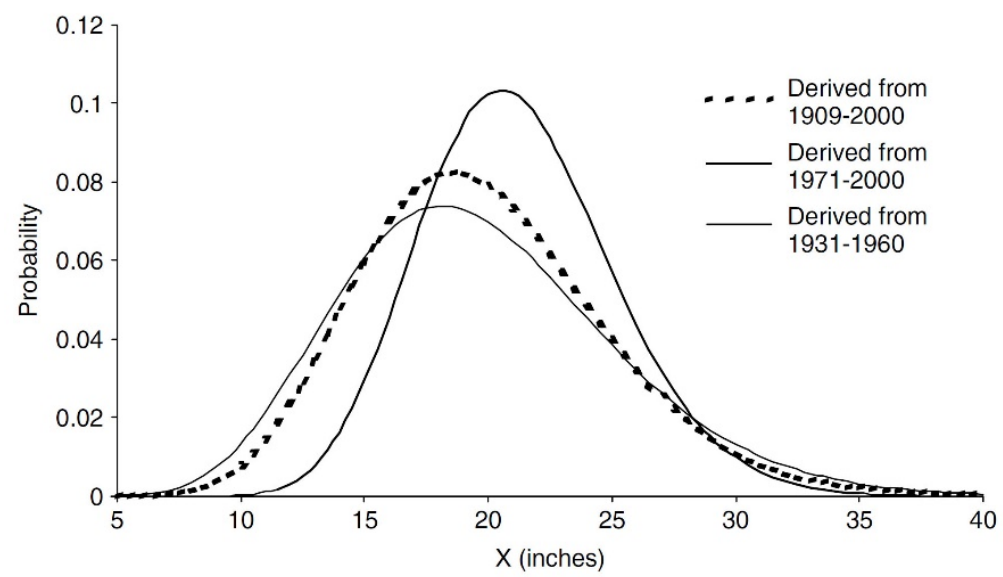

Figure 9. Two-parameter gamma PDF curves for 52-week SPI McCook, Nebraska. The heavy solid line denotes the PDF derived from the 1971-2000 records with $\alpha=29.5, \beta=$ 0.72. The dotted line denotes the PDF derived from the 1909-2000 records with $\alpha=15.87$, $\beta=1.25$. The thin solid line denotes the PDF derived from the 1931-60 records with $\alpha=$ $12.5, \beta=1.58$. 


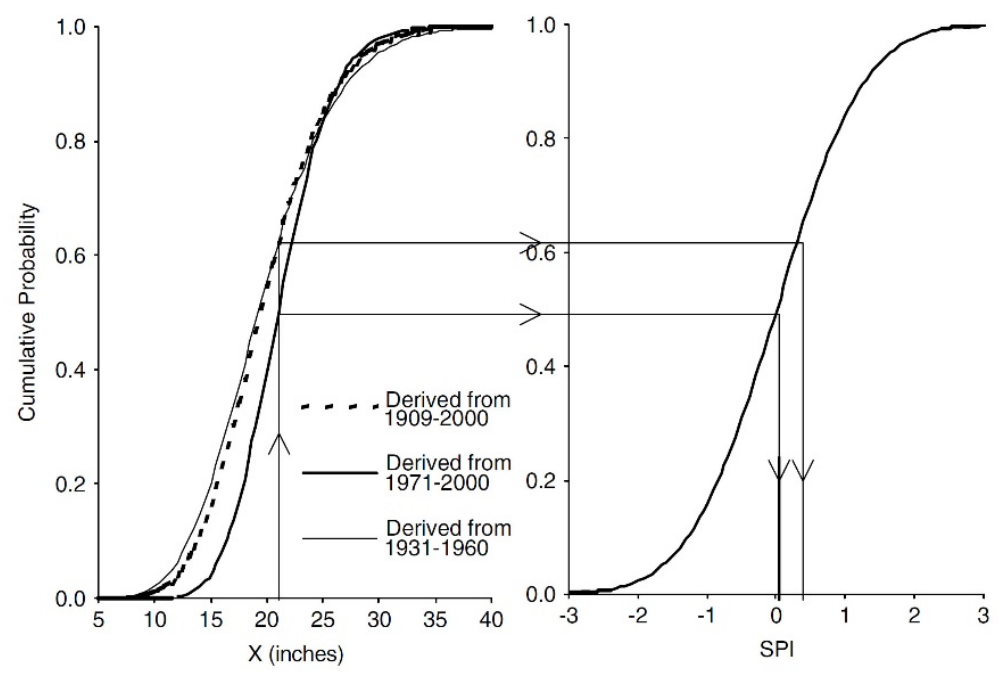

Figure 10. Equiprobability transformation from fitted gamma CDF to the standard normal distribution for 52-week SPI for McCook, Nebraska.

Based on figure 10, we can explain three facts observed in figure 4, which compares the SPI values derived from different lengths of record in those individual years for McCook. First, the long-time-scale SPI values for McCook in drought years from 1936 to 1938 are slightly different. This is because the CDFs derived for 1909-2000 and 1931-60 are similar. Second, the long-time-scale SPI values are slightly different during the wet period in 199294. This is because CDFs derived for 1909-2000 and 1971-2000 converge when precipitation is greater than a certain amount. Third, the long-time-scale SPI values in severe drought years from 2001 to 2003 are significantly different. This is because the CDFs derived for 1909-2000 and 1971-2000 diverge when precipitation is less than a certain amount.

As noted, the discrepancy between SPI values derived by the different lengths of record becomes larger when the time scale of SPI gets longer and drought intensifies. There are three reasons that lead to the large discrepancy. One is that the effective sample size is decreased when a long time scale is used. Furthermore, the effective sample size gets worse when drought intensifies because the SPI values are located on the left tail of a distribution.

\section{Conclusions}

The effect of the length of record used on SPI calculations was illustrated by comparing SPI values computed from different record lengths, and the reason for SPI value discrepancy was explored by investigating gamma distributions derived using different record lengths. The study shows that the SPI values derived from the different lengths of record are highly correlated for some stations. For other stations, however, SPI values derived from different lengths of record differ considerably as time scales get longer and drought 
intensifies. In this case, inconsistent conclusions will be obtained when the SPI values are compared spatially and temporally.

The study indicates that the change in the underlying precipitation distribution $(\alpha$ and $\beta$ ) from one time period to another affects the SPI values. It is concluded that the differences between the SPI values that are computed using different lengths of record are not considerable if the parameters over the time are close. If the precipitation pattern changes, then the SPI values derived from different lengths of record will be significantly different when droughts intensify and long time scales are used.

One needs to be aware that the conclusions are "universal." Although they are based on a Nebraska case study, they definitely can be extended to other regions.

Thus, we would like to make a few suggestions to the SPI user:

1. The SPI user should be aware that inconsistent conclusions could be obtained if different time lengths of precipitation record are involved in the SPI calculation.

2. The longer the length of record used in the SPI calculation, the more reliable the SPI values will be, especially for long-time-scale SPI values. Therefore, sound decisions probably need the longer length of record because the shorter one is likely not to capture the "signals" of climate variability.

3. It is appropriate to examine SPI values derived from a short length of record to monitor current conditions in the light of recent "climate." Under this circumstance, one should be aware that the reduced effective sample size leads to instability of the parameter estimates. If the parameter estimates have little confidence, then the resulting SPI values will also have little confidence.

Based on this study, we feel that there is a need to develop an SPI user's guide, which would help a person use the SPI more appropriately and accurately. The staff members of the NDMC are currently working on the user's guide, which may become available in late 2005 on the NDMC website (http://drought.unl.edu).

Acknowledgments - This study was supported by the National Science Foundation Digital Government Program and NDMC. We greatly appreciate Dr. Guttman, one anonymous reviewer, and Dr. Comrie for providing valuable and constructive comments and suggestions. This paper is University of Nebraska Agricultural Research Division Contribution Number 14624.

\section{References}

Anctil F, Larouche W, Viau AA. 2002. Exploration of the standardized precipitation index with regional analysis. Canadian Journal of Soil Science 82(1): 115-125.

Burroughs WJ. 2001. Climate Change: A Multidisciplinary Approach. Cambridge University Press: Cambridge, UK.

CCC. 2004. Colorado Climate Center. http://ulysses.atmos.colostate.edu/standardizedprecipitation.php [2004].

Edwards DC, McKee TB. 1997. Characteristics of 20th century drought in the United States at multiple scales. Atmospheric Science Paper No. 634, May; 1-30. 
Guttman NB. 1994. On the sensitivity of sample L moments to sample size. Journal of Climatology 7: 1026-1029.

Guttman NB. 1998. Comparing the Palmer drought index and the standardized precipitation index. Journal of the American Water Resources Association 34(1): 113-121.

Guttman NB. 1999. Accepting the standardized precipitation index: a calculation algorithm. Journal of the American Water Resources Association 35(2): 311-322.

Hayes M, Wilhite D, Svoboda M, Vanyarkho O. 1999. Monitoring the 1996 drought using the standardized precipitation index. Bulletin of the American Meteorological Society 80(3): 429-438.

Houghton JT, Callander BA, Varner SK (eds). 1992. Climate Change 1992: The Supplementary Report to the IPCC Scientific Assessment. Cambridge University Press: Cambridge, UK.

HPRCC. 2004. High Plains Regional Climate Center. http://hprcc.unl.edu [2004].

IANR. 2003. Institute of Agriculture and Natural Resources, University of Nebraska-Lincoln. http://ianrnews.unl.edu/static/0301162.shtml [2003].

Karl TR, Riebsame WE. 1984. The identification of 10- to 20-year temperature and precipitation fluctuations in the contiguous United States. Journal of Climate and Applied Meteorology 23: 950-966.

Keyantash J, Dracup JA. 2002. The quantification of drought: an evaluation of drought indices. The drought monitor. The Bulletin of the American Meteorological Society 83(8): 1167-1180.

Lamb PJ, Changnon Jr SA. 1988. On the "best" temperature and precipitation normals: The Illinois situation. Journal of Applied Meteorology 20: 1383-1419.

Lana X, Serra C, Burgueno A. 2001. Patterns of monthly rainfall shortage and excess in terms of the standardized precipitation index. International Journal of Climatology 21: 1669-1691.

Landsberg HE. 1975. The definition and determination of climate changes, fluctuations and outlooks. In Atmospheric Quality and Climatic Change, Kopec RJ (ed.), Papers of the Second Carolina Geographical Symposium.

Larson L. 1996. The great USA flood of 1993. http://www.nwrfc.noaa.gov/floods/papers/oh_2/great .htm [2003].

Lawson MP, Reiss A, Phillips R, Livingston K. 1971. Nebraska droughts: A study of their past chronological and spatial extent with implications for the future. Technical research project completion report, University of Nebraska-Lincoln.

Lloyd-Hughes B, Saunders MA. 2002. A drought climatology for Europe. International Journal of Climatology 22: 1571-1592.

Mauget SA. 2003. Multidecadal regime shifts in U.S. streamflow, precipitation, and temperature at the end of the twentieth century. Journal of Climate 16(23): 3905-3916.

McKee TB, Doesken NJ, Kleist J. 1993. The relationship of drought frequency and duration to time scales. In Proceeding of the Ninth Conference on Applied Climatology. American Meteorological Society: Boston; 179-184.

Min SK, Kwon WT, Park EH, Choi Y. 2003. Spatial and temporal comparisons of droughts over Korea with East Asia. International Journal of Climatology 23(2): 223-233.

NADSS. 2004. National Agricultural Decision Support System. http://nadss.unl.edu/ [2004].

NCDC. 2004. National Climatic Data Center. http://www.ncdc.noaa.gov/oa/climate/research/prelim/ drought/spi.html [2004].

NDMC. 2004. National Drought Mitigation Center. http://drought.unl.edu [2004].

Palmer WC. 1965. Meteorological drought. US Department of Commerce Weather Bureau Research Paper No. 45. 
Rouault M, Richard Y. 2003. Intensity and spatial extension of drought in South Africa at different time scales. Water SA 29(4): 489-500 (available online at http://www.wrc.org.za).

Seiler RA, Hayes MJ, Bressan L. 2002. Using the standardized precipitation index for flood risk monitoring. International Journal of Climatology 22(11): 1365-1376.

Skaggs RH. 1978. Climate change and persistence in western Kansas. Annals of the Association of American Geographers 68(1): 73-80.

Szalai S, Szinell C. 2000. Comparison of two drought indices for drought monitoring in Hungary-a case study. In Drought and Drought Mitigation in Europe, Vogt JV, Spmma F (eds). Kluwer: Dordrech; 161-166.

Triola MF. 1998. Elementary Statistics, seventh edition. Addison-Weseley.

Wilhite DA. 1981. An analysis of Nebraska's precipitation climatology: With emphasis on occurrence of dry conditions. The Agricultural Experiment Station, University of Nebraska-Lincoln.

Wilhite DA. 1983. Government response to the mid-1970s drought: With particular reference to the U.S. Great Plains. Journal of Climate and Applied Meteorology 22: 40-50.

Willmott CJ. 1981. On the validation of models. Physical Geography 2: 184-194.

WRCC. 2004. Western Regional Climate Center. http://www.wrcc.dri.edu/spi/spi.htm [2004]. 